\title{
Epidemiology and health care utilization of patients suffering from Huntington's disease in Germany: real world evidence based on German claims data
}

\author{
Christoph OhImeier ${ }^{1 *}$, Kai-Uwe Saum², Wolfgang Galetzka ${ }^{3}$, Dominik Beier ${ }^{3}$ and Holger Gothe ${ }^{1,4,5}$
}

\begin{abstract}
Background: Huntington's disease (HD) is a rare, genetic, neurodegenerative and ultimately fatal disease with no cure or progression-delaying treatment currently available. HD is characterized by a triad of cognitive, behavioural and motor symptoms. Evidence on epidemiology and management of HD is limited, especially for Germany. This study aims to estimate the incidence and prevalence of HD and analyze the current routine care based on German claims data.

Methods: The source of data was a sample of the Institute for Applied Health Research Berlin (InGef) Research Database, comprising data of approximately four million insured persons from approximately 70 German statutory health insurances. The study was conducted in a retrospective cross-sectional design using 2015 and 2016 as a two-year observation period. At least two outpatient or inpatient ICD-10 codes for HD (ICD-10: G10) during the study period were required for case identification. Patients were considered incident if no HD diagnoses in the 4 years prior to the year of case identification were documented. Information on outpatient drug dispensations, medical aids and remedies were considered to describe the current treatment situation of HD patients.

Results: A 2-year incidence of 1.8 per 100,000 persons (95\%-Confidence interval (Cl): 1.4-2.4) and a 2-year period prevalence of 9.3 per 100,000 persons (95\%-Cl: 8.3-10.4) was observed. The prevalence of HD increased with advancing age, peaking at 60-69 years (16.8 per 100,000 persons; 95\%-Cl: 13.4-21.0) and decreasing afterwards. The most frequently observed comorbidities and disease-associated symptoms in HD patients were depression (42.9\%), dementia (37.7\%), urinary incontinence (32.5\%), extrapyramidal and movement disorders (30.5\%), dysphagia (28.6\%) and disorders of the lipoprotein metabolism (28.2\%).

The most common medications in HD patients were antipsychotics (66.9\%), followed by antidepressants (45.1\%). Anticonvulsants (16.6\%), opioids (14.6\%) and hypnotics (9.7\%) were observed less frequently.

Physical therapy was the most often used medical aid in HD patients (46.4\%). Nursing services and speech therapy were used by 27.9 and $22.7 \%$ of HD patients, respectively, whereas use of psychotherapy was rare (3.2\%).
\end{abstract}

Conclusions: Based on a representative sample, this study provides new insights into the epidemiology and routine care of HD patients in Germany, and thus, may serve as a starting point for further research.

Keywords: Huntington's disease, Claims data analysis, Health care utilization, Epidemiology, Germany, Prevalence, Incidence

\footnotetext{
* Correspondence: christoph.ohlmeier@iges.com

${ }^{1}$ IGES Institut GmbH, Friedrichstraße 180, 10117 Berlin, Germany

Full list of author information is available at the end of the article
}

(c) The Author(s). 2019 Open Access This article is distributed under the terms of the Creative Commons Attribution 4.0 International License (http://creativecommons.org/licenses/by/4.0/), which permits unrestricted use, distribution, and reproduction in any medium, provided you give appropriate credit to the original author(s) and the source, provide a link to the Creative Commons license, and indicate if changes were made. The Creative Commons Public Domain Dedication waiver (http://creativecommons.org/publicdomain/zero/1.0/) applies to the data made available in this article, unless otherwise stated. 


\section{Background}

Huntington's disease (HD) is a rare, genetic, neurodegenerative and ultimately fatal disease with no cure or progression-delaying treatment currently available. HD is caused by a trinucleotide (cytosine-adenine-guanine [CAG]) repeat expansion in the huntingtin gene [1-3]. Typically, HD patients present with a triad of cognitive, behavioral and motor symptoms [3-5], which lead to increasing disability, functional decline and loss of independence $[2,5]$. This results in complex patient needs, which are best addressed with interdisciplinary teams consisting of general practitioners, specialists and other health care professionals, e. g. nurses, physical and speech therapists or dietitians [4].

With an estimated prevalence of 3.6 to 5.7 per 100,000 in regions mainly comprising residents of Caucasian descent [6, 7], HD is considered a rare disease in Europe [8]. Although 'gene silencing' could be a potential therapeutic strategy in the future [9], HD is currently incurable, and therapeutic approaches focus on symptom management and maintaining the quality of life.

In Germany, information about the epidemiology and management of HD is scarce. German studies are restricted to specific regions and are outdated [10, 11], limiting the generalizability and validity of these studies to current healthcare practice. Furthermore, international studies are only partially transferable to the German healthcare system. Current, real-world data could be used to improve healthcare planning in order to better meet the needs of affected patients [12]. Therefore, the aim of the present study was to fill this evidence gap for Germany by (i) estimating the incidence and period prevalence of $\mathrm{HD}$, (ii) characterizing the demographics and comorbidities of HD patients and (iii) describing the current routine treatments and associated costs.

\section{Methods}

\section{Data source}

The data source for the present study was the Institute for Applied Health Research Berlin (InGef) Research Database. The InGef Research Database is an anonymized claims database with approximately 70 German statutory health insurances (SHI) contributing longitudinal data from approximately 6.7 million persons. For this analysis, the InGef Research Database was condensed to a sample of approximately 4 million persons considered representative of the German population in terms of age and sex, and showing high external validity regarding morbidity, mortality and prescription drug use [13]. This database also contains information on hospitalizations, outpatient physician visits and outpatient drug prescriptions. The hospital data comprises information on the date of admission and discharge, the reason for discharge, diagnostic and therapeutic procedures with the exact date as well as diagnoses, which can be distinguished in hospital main discharge diagnoses and secondary diagnoses. The outpatient data also comprises information on diagnostic and therapeutic procedures with their exact date. Outpatient diagnoses can be distinguished by confirmed diagnoses, suspected diagnoses, status post diagnoses and diagnoses ruled out. Inpatient and outpatient diagnoses are coded according to the German Modification of the International Classification of Diseases 10th Revision (ICD-10-GM). Data on outpatient prescriptions of reimbursed drugs comprise information on the prescription, the date of prescription and the pharmaceutical reference number. The anatomical-therapeutic-chemical code (ATC-code), the defined daily dose (DDD), the packaging size as well as the strength and formulation of the drug can be linked for each dispensed drug based on a pharmaceutical reference database [13].

\section{Study design}

To estimate the prevalence and incidence of HD, a retrospective, cross-sectional study was carried out. This study covered an observation period of 24 months (1 January 2015 to 31 December 2016). This study was descriptive; thus, no hypotheses were pre-specified.

A 24-month observation period was chosen instead of e. g. a 12-month observation period in order to be able to identify a sufficiently large number of HD cases and thus ensure a comparatively robust estimation of the HD burden. Furthermore, if case numbers had been too small, data protection reasons would not have allowed a publication of respective results and would therefore lead to less meaningful results.

\section{Study population}

Insured persons were included if they had continuous insurance coverage during the entire study period or until death during the study period. Analyses on characteristics and prescribed medication were carried out in the subpopulation of patients fulfilling the identification criteria for HD.

\section{Identification of patients with Huntington's disease}

Patients were identified as prevalent HD cases if at least two diagnoses of HD (ICD-10-GM: G10) were recorded during the study period. Hospital main discharge diagnoses, hospital secondary discharge diagnoses and confirmed outpatient diagnoses were considered for HD case identification. An incident HD case was assumed if patients additionally had no documented hospital main discharge diagnoses, hospital secondary discharge diagnoses or confirmed outpatient diagnoses in the four calendar years prior to the year of case identification. 


\section{Ascertainment of comorbidities and disease-associated symptoms}

The burden of specific comorbidities and diseaseassociated symptoms was ascertained by considering confirmed outpatient diagnoses, hospital main discharge diagnoses and hospital secondary diagnoses documented during the 24-months observation period. One diagnosis was sufficient to be identified as having the comorbidity or disease-associated symptom (see Additional file 3). A data-driven approach of the most frequently documented diseases was carried out based on the three-digit level of the ICD-10-GM code (see Additional file 4).

\section{Ascertainment of prescribed drugs, medical aids and remedies}

All analyses regarding HD treatment were based on the 24-month observation period. Outpatient drugs were classified by three- or four-digit level of the ATC-code; specific drug were classified by seven-digit level of the ATC-code. One dispensation of a drug or drug class was sufficient to meet the criteria. Furthermore, the sum of dispensed DDD and the accumulated costs (pharmacy retail price) during the 24-month period were ascertained. In addition, the most frequently dispensed drugs were analyzed based on the seven-digit level of the ATC-code.

At least one claim of medical aids and remedies of a respective service was sufficient to meet the criteria. Accumulated costs to the SHI during the observation period were calculated for each respective care service.

\section{Statistical analyses}

The two-year incidence and the two-year period prevalence of HD were calculated by dividing the number of incident and prevalent HD cases, respectively, by the study population. Both estimates are presented per 100,000 persons.

The proportion of patients with a specific comorbidity or disease-associated symptom; use of a specific drug or class; or use of medical aid or remedy were calculated by dividing the number of patients fulfilling the respective criteria by the number of persons in the HD population.

Mean costs of health service was calculated by dividing the sum of costs by the number of patients receiving the respective health service. To ascertain the mean costs per year, the mean costs were divided by two, assuming that the mean resource use was equally distributed in both calendar years. The analyses of the costs of HD treatment are therefore purely descriptive. A more comprehensive analysis of the economic disease burden was not the subject of this study.

All analyses were carried out stratified by sex.

All analyses were carried out using $\mathrm{R}$, version 3.5.0.

\section{Results}

Patient characteristics

Of the 308 patients identified with HD, 45.1\% were female (Table 1). The mean age of prevalent HD patients was 59.8 years (standard deviation $(\mathrm{SD})$ : 13.6) with the majority being between 50 and 69 years old.

The most common comorbidity or disease-associated symptom was depression (42.9\%), which was slightly more frequent in women than in men (Table 2). Extrapyramidal and movement disorders were diagnosed in $30.5 \%$ of HD patients, and dysphagia was diagnosed in $28.6 \%$ of HD patients. Additionally, the data-driven analysis showed that more than one third of the HD patients were affected by dementia, approximately $30 \%$ had urinary incontinence, and approximately $30 \%$ had disorders of the lipoprotein metabolism. Female HD patients were more frequently affected by lipoprotein disorders than males (see Additional file 2).

\section{Incidence and prevalence of HD}

The overall two-year incidence of HD was 1.8 per 100 , 000 persons (95\%-Confidence interval (CI): 1.4-2.4). The overall two-year prevalence of HD (9.3 per 100,000; 95\%-CI: $8.3-10.4)$ was higher in men $(10.2$ per 100,000 ; 95\%-CI: 8.8-11.9) than in women (8.3 per 100,000 ; $95 \%$ CI: 7.0-9.8). The prevalence of HD increased with advancing age, peaking at 60-69 years (16.8 per 100,000 persons; 95\%-CI: 13.4-21.0) and declining in patients aged 70 years or older (Table 3 ).

\section{Use of drugs, medical aids and remedies}

Antipsychotic drugs were the most frequently observed dispensed drugs in prevalent HD patients with $66.9 \%$ receiving at least one dispensation of antipsychotics, mean dispensed DDD per year of 386.5 and associated mean costs of $€ 556.64$ per year (Table 4). Tiapride was the most frequently dispensed antipsychotic drug (46.8\% of HD patients) (see Additional file 1). Furthermore, 45.1\% of the HD patients received antidepressants with mean costs of $€ 125.22$ per year and with mean DDD of 352.3 per year. The most frequently observed antidepressant drug was mirtazapine with $20.5 \%$ of HD patients with at least one dispensation (see Additional file 1). Use of anticonvulsants, hypnotics and opioids was observed in substantially fewer patients. Sex-specific differences regarding drug use were rarely observed. However, mean annual DDD of antipsychotic drugs were higher in women compared to men. Besides tiapride and mirtazapine metamizole $(29.5 \%)$, ibuprofen $(25.3 \%)$ and pantoprazole $(24.4 \%)$ were the most frequently dispensed drugs in HD patients. Tetrabenazine, which is approved for the treatment of hyperkinetic movement disorders in HD, was dispensed to $18.5 \%$ of HD patients. 
Table 1 Characteristics of patients with prevalent HD in 2015 and 2016

\begin{tabular}{|c|c|c|c|c|c|c|}
\hline & \multicolumn{2}{|c|}{ Women $(n=139)$} & \multicolumn{2}{|c|}{ Men $(n=169)$} & \multicolumn{2}{|c|}{ All $(n=308)$} \\
\hline & $n$ & $\%$ & $n$ & $\%$ & $n$ & $\%$ \\
\hline \multicolumn{7}{|l|}{ Age } \\
\hline $0-29$ years & $<5$ & / & / & / & 6 & $1.9 \%$ \\
\hline 30-39years & 5 & $3.6 \%$ & 10 & $5.9 \%$ & 15 & $4.9 \%$ \\
\hline 40-49 years & 18 & $12.9 \%$ & 29 & $17.2 \%$ & 47 & $15.3 \%$ \\
\hline $50-59$ years & 38 & $27.3 \%$ & 48 & $28.4 \%$ & 86 & $27.9 \%$ \\
\hline 60-69 years & 42 & $30.2 \%$ & 35 & $20.7 \%$ & 77 & $25.0 \%$ \\
\hline 70-79 years & 24 & $17.3 \%$ & 34 & $20.1 \%$ & 58 & $18.8 \%$ \\
\hline$>=80$ years & 9 & $6.5 \%$ & 10 & $5.9 \%$ & 19 & $6.2 \%$ \\
\hline All & 139 & $100.0 \%$ & 169 & $100.0 \%$ & 308 & $100.0 \%$ \\
\hline Mean age (mean, SD) & 60.4 & 13.3 & 59.4 & 13.4 & 59.8 & 13.6 \\
\hline \multicolumn{7}{|l|}{ Sex } \\
\hline Female & 139 & $100.0 \%$ & - & - & 139 & $45.1 \%$ \\
\hline Male & - & - & 169 & $100.0 \%$ & 169 & $54.9 \%$ \\
\hline
\end{tabular}

Numbers which are too low or might allow indirect calculability of too low case numbers cannot be displayed due to data protection reasons

SD Standard deviation

Physical therapy was the most frequent medical aid with $46.4 \%$ of HD patients receiving at least one prescription. Physical therapy was associated with the mean annual costs of $€ 793.02$. Speech therapy was prescribed to $22.7 \%$ of HD patients with mean annual costs of $€ 1073.04$ per year. In addition, $18.2 \%$ of patients with HD used a wheel chair and $9.4 \%$ a walking aid. Sexspecific differences regarding use of medical aids and remedies were rarely observed.

\section{Discussion}

\section{Summary of findings}

Based on representative German claims data, a two-year incidence for HD of 1.8 per 100,000 persons and a twoyear prevalence of 9.3 per 100,000 persons was observed.
This study also showed that depression was the most frequent comorbidity or disease-associated symptom in HD patients. Furthermore, two thirds of HD patients received antipsychotics during the observation period.

\section{Discussion of findings}

Several systematic reviews on the prevalence of HD have been published, which all point towards a heterogeneous body of evidence $[6,7,14]$. According to Pringsheim et al., pooled evidence from North America, Europe and Australia resulted in a prevalence of 5.70 per 100,000 (95\% CI: $4.42-7.35$ ) which ranged from 1.56 to 12.08 per 100,000 persons [6]. Rawlins et al. reported a prevalence of 3.60 (95\%-CI: 3.50 3.69) for Western Europe which ranged from 0.53 to

Table 2 Pre-specified comorbidities and disease-associated symptoms of patients with prevalent HD in 2015 and 2016

\begin{tabular}{|c|c|c|c|c|c|c|}
\hline & \multicolumn{2}{|c|}{ Women $(n=139)$} & \multicolumn{2}{|c|}{ Men $(n=169)$} & \multicolumn{2}{|c|}{ All $(n=308)$} \\
\hline & $\mathrm{n}$ & $\%$ & $\mathrm{n}$ & $\%$ & $\mathrm{n}$ & $\%$ \\
\hline $\mathrm{ADHD}$ & 8 & $5.8 \%$ & 8 & $4.7 \%$ & 16 & $5.2 \%$ \\
\hline Anxiety & 26 & $18.7 \%$ & 12 & $7.1 \%$ & 38 & $12.3 \%$ \\
\hline Bipolar disorder & $<5$ & / & / & / & $<5$ & / \\
\hline Depression & 64 & $46.0 \%$ & 68 & $40.2 \%$ & 132 & $42.9 \%$ \\
\hline Diabetes mellitus & 16 & $11.5 \%$ & 18 & $10.7 \%$ & 34 & $11.0 \%$ \\
\hline Dysphagia & 35 & $25.2 \%$ & 53 & $31.4 \%$ & 88 & $28.6 \%$ \\
\hline Extrapyramidal and movement disorders & 42 & $30.2 \%$ & 52 & $30.8 \%$ & 94 & $30.5 \%$ \\
\hline Insomnia & 20 & $14.4 \%$ & 21 & $12.4 \%$ & 41 & $13.3 \%$ \\
\hline Obsessive compulsive disorder & $<5$ & / & / & / & $<5$ & / \\
\hline Osteoarthritis & 31 & $22.3 \%$ & 24 & $14.2 \%$ & 55 & $17.9 \%$ \\
\hline Other systemic atrophies (excl. HD) & $<5$ & / & / & / & 8 & $2.6 \%$ \\
\hline
\end{tabular}

Numbers which are too low or might allow indirect calculability of too low case numbers cannot be displayed due to data protection reasons 
Table 3 Age- and sex-stratified two-year prevalence of HD

\begin{tabular}{|c|c|c|c|c|c|c|c|c|c|c|c|c|}
\hline & \multicolumn{3}{|c|}{ Women $(n=139)$} & \multirow[t]{2}{*}{$95 \%-\mathrm{Cl}$} & \multicolumn{3}{|c|}{ Men $(n=169)$} & \multirow[t]{2}{*}{$95 \%-\mathrm{Cl}$} & \multicolumn{3}{|l|}{ All $(n=308)$} & \multirow[t]{2}{*}{$95 \%-С$} \\
\hline & $\begin{array}{l}\mathrm{N} \\
\text { population }\end{array}$ & $\begin{array}{l}\mathrm{n} \\
\text { cases }\end{array}$ & $\begin{array}{l}\text { Prevalence per } \\
100,000 \text { persons }\end{array}$ & & $\begin{array}{l}\mathrm{N} \\
\text { population }\end{array}$ & $\begin{array}{l}\mathrm{n} \\
\text { cases }\end{array}$ & $\begin{array}{l}\text { Prevalence per } \\
100,000 \text { persons }\end{array}$ & & $\begin{array}{l}\mathrm{N} \\
\text { population }\end{array}$ & $\begin{array}{l}\mathrm{n} \\
\text { cases }\end{array}$ & $\begin{array}{l}\text { Prevalence per } \\
100,000 \text { persons }\end{array}$ & \\
\hline \multicolumn{13}{|l|}{ Age } \\
\hline $\begin{array}{l}0-29 \\
\text { years }\end{array}$ & 426,131 & $<5$ & - & & 440,649 & / & - & & 866,780 & 6 & 0.7 & $0.3-1.5$ \\
\hline $\begin{array}{l}30-39 \\
\text { years }\end{array}$ & 173,714 & 5 & 2.9 & $1.2-6.7$ & 172,856 & 10 & 5.8 & $\begin{array}{l}3.1- \\
10.6\end{array}$ & 346,570 & 15 & 4.3 & $2.6-7.1$ \\
\hline $\begin{array}{l}40-49 \\
\text { years }\end{array}$ & 221,720 & 18 & 8.1 & $\begin{array}{l}5.1- \\
12.8\end{array}$ & 223,105 & 29 & 13.0 & $\begin{array}{l}9.1- \\
18.7\end{array}$ & 444,825 & 47 & 10.6 & $\begin{array}{l}7.9- \\
14.0\end{array}$ \\
\hline $\begin{array}{l}50-59 \\
\text { years }\end{array}$ & 284,651 & 38 & 13.3 & $\begin{array}{l}9.7- \\
18.3\end{array}$ & 289,813 & 48 & 16.6 & $\begin{array}{l}12.5- \\
22.0\end{array}$ & 574,464 & 86 & 15.0 & $\begin{array}{l}12.1- \\
18.5\end{array}$ \\
\hline $\begin{array}{l}60-69 \\
\text { years }\end{array}$ & 235,666 & 42 & 17.8 & $\begin{array}{l}13.2- \\
24.1\end{array}$ & 222,871 & 35 & 15.7 & $\begin{array}{l}11.3- \\
21.8\end{array}$ & 458,537 & 77 & 16.8 & $\begin{array}{l}13.4- \\
21.0\end{array}$ \\
\hline $\begin{array}{l}70-79 \\
\text { years }\end{array}$ & 193,336 & 24 & 12.4 & $\begin{array}{l}8.3- \\
18.5\end{array}$ & 192,799 & 34 & 17.6 & $\begin{array}{l}12.6- \\
24.6\end{array}$ & 386,135 & 58 & 15.0 & $\begin{array}{l}11.6- \\
19.4\end{array}$ \\
\hline $\begin{array}{l}>=80 \\
\text { years }\end{array}$ & 141,035 & 9 & 6.4 & $\begin{array}{l}3.4- \\
12.1\end{array}$ & 107,292 & 10 & 9.3 & $\begin{array}{l}5.1- \\
17.2\end{array}$ & 248,327 & 19 & 7.7 & $\begin{array}{l}4.9- \\
12.0\end{array}$ \\
\hline All & $1,676,253$ & 139 & 8.3 & $7.0-9.8$ & $1,649,385$ & 169 & 10.2 & $\begin{array}{l}8.8- \\
11.9\end{array}$ & $3,325,638$ & 308 & 9.3 & $\begin{array}{l}8.3- \\
10.4\end{array}$ \\
\hline
\end{tabular}

Cl Confidence interval

10.85 per 100,000 persons [7]. Baig et al. presented heterogeneous study results with a prevalence ranging from 0.96 to 13.7 per 100,000 persons for North America, Europe and Australia [14]. Our estimate, at 9.3 per 100,000 persons, is higher than reported in most systematic reviews. This could be due to several reasons. Firstly, the studies in the reviews - including those from German population samples - are mostly older than 20 years $[10,11]$. Evidence suggests that the prevalence of HD has increased during the past 30 years [7, 15], because of higher awareness among physicians [7], longer survival of the patients [16] and

Table 4 Use of drugs, medical aids and remedies of prevalent HD patients in 2015 and 2016

\begin{tabular}{|c|c|c|c|c|c|c|c|c|c|c|c|c|}
\hline & \multicolumn{4}{|c|}{ Women $(n=139)$} & \multicolumn{4}{|c|}{ Men $(n=169)$} & \multicolumn{4}{|c|}{ All $(n=308)$} \\
\hline & $\mathrm{n}$ & $\%$ & $\begin{array}{l}\text { Mean costs per } \\
\text { patient and year }\end{array}$ & $\begin{array}{l}\text { Mean } \\
\text { DDD per } \\
\text { year }\end{array}$ & $\mathrm{n}$ & $\%$ & $\begin{array}{l}\text { Mean costs per } \\
\text { patient and year }\end{array}$ & $\begin{array}{l}\text { Mean } \\
\text { DDD per } \\
\text { year }\end{array}$ & $\mathrm{n}$ & $\%$ & $\begin{array}{l}\text { Mean costs per } \\
\text { patient and year }\end{array}$ & $\begin{array}{l}\text { Mean } \\
\text { DDD per } \\
\text { year }\end{array}$ \\
\hline \multicolumn{13}{|l|}{ Drugs } \\
\hline Anticonvulsants & 21 & $15.1 \%$ & $153.76 €$ & 132.9 & 30 & $17.8 \%$ & $146.93 €$ & 124.7 & 51 & $16.6 \%$ & $149.74 €$ & 128.1 \\
\hline Antidepressants & 62 & $44.6 \%$ & $129.50 €$ & 356.4 & 77 & $45.6 \%$ & $121.78 €$ & 349.1 & 139 & $45.1 \%$ & $125.22 €$ & 352.3 \\
\hline Antipsychotics & 91 & $65.5 \%$ & $633.34 €$ & 467.6 & 115 & $68.0 \%$ & $495.95 €$ & 322.2 & 206 & $66.9 \%$ & $556.64 €$ & 386.5 \\
\hline Hypnotics & 15 & $10.8 \%$ & $67.54 €$ & 86.6 & 15 & $8.9 \%$ & $43.22 €$ & 84.0 & 30 & $9.7 \%$ & $55.38 €$ & 85.3 \\
\hline Opioids & 20 & $14.4 \%$ & $214.81 €$ & 47.6 & 25 & $14.8 \%$ & $90.98 €$ & 33.7 & 45 & $14.6 \%$ & $146.02 €$ & 39.9 \\
\hline \multicolumn{13}{|l|}{ Medical aids } \\
\hline Nursing ${ }^{a}$ & 40 & $28.8 \%$ & - & - & 46 & $27.2 \%$ & - & - & 86 & $27.9 \%$ & - & - \\
\hline $\begin{array}{l}\text { Physical } \\
\text { therapy }\end{array}$ & 65 & $46.8 \%$ & $795.43 €$ & - & 78 & $46.2 \%$ & $791.01 €$ & - & 143 & $46.4 \%$ & $793.02 €$ & - \\
\hline Psychotherapy & / & / & / & - & $<5$ & / & / & - & 10 & $3.2 \%$ & $553.39 €$ & - \\
\hline Speech therapy & 28 & $20.1 \%$ & $1232.98 €$ & - & 42 & $24.9 \%$ & $966.42 €$ & - & 70 & $22.7 \%$ & $1073.04 €$ & - \\
\hline \multicolumn{13}{|l|}{ Remedies } \\
\hline Walking aid & 14 & $10.1 \%$ & $128.33 €$ & - & 15 & $8.9 \%$ & $61.28 €$ & - & 29 & $9.4 \%$ & $93.65 €$ & - \\
\hline Wheelchair use & 27 & $19.4 \%$ & $481.91 €$ & - & 29 & $17.2 \%$ & $591.71 €$ & - & 56 & $18.2 \%$ & $538.77 €$ & - \\
\hline
\end{tabular}


progression of the baby-boomers' generation into the manifest phase of HD [17]. Thus, a higher prevalence in our study was to be expected. Secondly, there seems to be a considerably higher HD prevalence in Caucasian populations compared to non-Caucasian populations $[7,18,19]$. The higher prevalence in the present study compared to the reviews could be explained by comparatively high proportion of residents with Caucasian descent in Germany. A recent study in the United Kingdom (UK) observed a prevalence of 12.3 per 100,000 persons for patients older than 20 years [15], a prevalence comparable to that of our study. Evans et al., whose research is based on the General Practice Research Database (GPRD; now Clinical Practice Research Datalink (CPRD)) comprising anonymized medical records from the primary care setting, analyzed data between 1990 and 2010 . During this period, the database grew from approximately 650,000 to more than $3,500,000$ patient records, allowing them to determine the prevalence in narrow age categories and in specific regions. Similar to our results, Evans et al. found only slight differences in the average prevalence for women (10.4 per 100,000 persons) and men ( 9.4 per 100,000 persons). However, they believe their estimates to be too low due to undetected cases of this rare condition [15]. Regarding the higher prevalence in older age groups, our findings generally align with others [20]. Nevertheless, in other studies, the average prevalence peaks between 51 and 60 years [15] and 60-64 years [20], whereas we found the highest prevalence between 60 and 69 years.

In addition, several studies have determined the incidence of HD. In their systematic review, Pringsheim and colleagues reveal a mean incidence of 0.4 per 100,000 persons per year with a higher incidence in studies including non-Asian populations (0.1-0.8 per 100,000 persons) than in studies with populations of Asian descent (0.05-0.1 per 100,000 persons) [6]. A study from Italy, which was based on administrative data and medical records, estimated the incidence of HD to be 0.3 per 100 , 000 persons [21]. In another study based on CPRD data, an incidence of 0.7 per 100,000 persons was observed with no trend in the incidence of HD over time (19902010) [22]. The incidence of HD determined in our study is comparatively high (1.8 per 100,000 persons). The difference, however, is comparatively small considering a two-year observation period chosen in our study.

Depression is a common comorbidity / disease-associated symptom of HD discussed in the literature. Our results of the depression rate within the HD patient population were consistent with previous research [23, 24], although we could not distinguish between HD stages due to the type of our underlying dataset. A comparison of our data with self- reported depression and anxiety data in a Norwegian cohort using the EQ-5D-3 L instrument [25] is not valid because evidence from studies that screen validated questionnaires point to an underestimation of the frequency of depression in claims data [26]. However, at the same time, German claims-data based studies revealed higher estimations of the prevalence of depression compared to national survey data [27]. According to the authors, this may be due to a lesser willingness to provide information on sensitive topics in interview situations compared to conversations with a familiar physician [27]. In addition, persons with severe depressions seem to be underrepresented in the study by Frank et al., which also might have contributed to a lower prevalence of depression in survey data compared to claims data [28].

Around 38\% of HD patients in our sample had dementia as a comorbidity / disease-associated symptom. However, comparisons with other studies are difficult, as no consistent criteria were applied in these studies. Due to cognitive impairments, which can be present even decades before the diagnosis $[29,30]$ and could manifest in performance at work, managing finances or safe driving [31], a general definition of dementia in HD might be difficult and criteria for the diagnosis of dementia cannot be applied 1:1 to comorbid dementia in HD patients (for comprehensive discussion see [32, 33]). Since varying definitions of dementia in HD may also affect the coding behavior of physicians, claims-data based analyses of the dementia burden in HD populations must therefore currently be interpreted cautiously.

Anderson et al. [34] studied the healthcare utilization in the United States of America (USA) among Medicaidand commercial-insured HD patients based on claims data. They report home assistance (which does not equate to nursing in this study) and physical therapy (with a usage rate between 37.1 and $64.0 \%$, depending on condition stage and insurance type) to be the most frequent interventions. Our result of $46.4 \%$ of HD patients using physical therapy were within that range. Similarly, the proportion of HD patients in our sample using speech therapy and wheelchairs is within the range reported by Anderson et al. In addition, we report nearly the same percentage of patients using walking aids (around 9.5\%) [34].

More than half of the HD patients in the sample were given antipsychotics. However, the prevalence of psychoses in HD patients seems to be considerably lower. A study analyzing factors contributing to psychosis in HD based on the Enroll-HD database, found 10.8\% of HD patients with a history of psychosis [35]. Instead, chorea is frequently treated with antipsychotics, especially in Europe [36, 37]. In a survey among HD experts, $50 \%$ of European respondents would choose tiapride as first choice therapy for treating chorea [37]. Therefore, the 
high use of antipsychotics in general and tiapride in particular (46.8\% of the sample), hints at the dispension to treat mainly motor deficits. Furthermore, dopamine antagonists like tiapride may show beneficial effects on HD patients regarding mood stabilization, sleep disturbances and the prevention of weight loss which might have also contributed to the comparatively high use of antipsychotics [38, 39].

Although studies on HD about direct and societal costs exist $[24,40]$, comparability with the present study is limited. This is because of varying research objectives, discrepancies in the displaying of the cost types, and large differences in the organization of healthcare between Germany, the UK and the USA.

\section{Strengths and limitations}

The main strength of this study is the large, unselected and supra-regional sample allowing robust estimations of the epidemiology, comorbidity or disease-associated symptoms and healthcare utilization for HD patients. Furthermore, recall and selection bias, both being a considerable methodological challenge in health services research, could be avoided since this study was based on claims data and did not depend on patient recall or the willingness to participate.

Although we based our findings on representative data, our findings should be interpreted with caution. Due to the cross-sectional design, it was not possible to address changing utilization or trends over time, and we cannot claim a causal relationship of, for example, comorbidity / disease-associated symptoms and drug use. Thus, our study is primarily descriptive. In addition, as we derive our findings from claims data, some limitations regarding this form of information should be considered. First, the nursing sector was not comprised by the database. Respective analyses were nevertheless feasible, since specific outpatient codes indirectly pointed towards use of nursing services. Consequently, the proportion of HD patients with use of nursing services is underestimated and costs could not be analyzed. Informal care, which is a large part of healthcare for the patients, could not be addressed in this study as well. Second, because of a lack of information about the severity of the condition, we were not able to depict the healthcare utilization stratified by stage, which could be of particular interest to healthcare planning. Furthermore, there is a gap between coding a healthcare service and actual utilization; for example, prescription of drugs does not imply full adherence to the medication plan. It should also be considered, that the insidious onset of HD might lead to a delayed diagnosis and therefore to an underestimation of epidemiological estimates.

\section{Conclusion}

To our knowledge, this study is the first comprehensive and supra-regional analysis of epidemiological measures and resource use in patients with HD in Germany. Based on a large and representative sample, this study provides new insights into the characteristics of the patients and their routine care. Thus, this study may serve as a starting point for further research, such as analyses describing treatment pathways and assessing the quality of intersectoral care, which would subsequently allow further development of the care of patients with HD in Germany.

\section{Supplementary information}

Supplementary information accompanies this paper at https://doi.org/10. 1186/s12883-019-1556-3.

Additional file 1. Most frequently used drugs (7-digit ATC level) in prevalent HD patients in 2015 and 2016

Additional file 2. Most frequently observed comorbidities and diseaseassociated symptoms (3-digit ICD 10 level) in patients with prevalent HD in 2015 and 2016

Additional file 3. Operationalization of pre-specified approach for identification of comorbidities and disease-associated symptoms

Additional file 4. Operationalization of data driven approach for identification of comorbidities and disease-associated symptoms

\section{Abbreviations}

ATC: Anatomical-therapeutic-chemical; CAG: Cytosine-adenine-guanine; Cl: Confidence interval; CPRD: Clinical Practice Research Datalink; DDD: Defined daily dose; GPRD: General Practice Research Database; HD: Huntington's Disease; ICD-10-GM: German Modification of the International Classification of Diseases 10th Revision; InGef: Institute for Applied Health Research Berlin; SHI: Statutory health insurance; UK: United Kingdom; USA: United States of America

\section{Acknowledgements}

Editorial review of this manuscript was provided by Physicians World Europe GmbH (Mannheim, Germany) funded by Roche Pharma AG (GrenzachWyhlen, Germany).

\section{Authors' contributions}

$\mathrm{CO}$ and $\mathrm{HG}$ were involved in the design of the study, the analysis and interpretation of data, and in writing the manuscript. KUS was involved in the design of the study, in the interpretation of data, and in writing the manuscript. WG and DB were involved in the analysis and interpretation of data, and in writing the manuscript. All authors read and approved the final manuscript.

\section{Funding}

This study was funded by Roche Pharma AG. The authors had complete autonomy for the process of establishing the protocol, carrying out the analyses and interpreting the results. This also includes the full right to publish the results without limitation.

\section{Availability of data and materials}

The authors are not allowed to share the analysis datasets of the current study due to data protection regulations.

\section{Ethics approval and consent to participate}

All patient-level data in the InGef research database are de-identified to comply with German data protection regulations. Use of the study database for health services research is therefore fully compliant with German federal law and, accordingly, institutional review board/ethical approval and informed consent of the patient was not needed. 


\section{Consent for publication}

Not applicable.

\section{Competing interests}

This study was funded by Roche Pharma AG. The authors had complete autonomy for the process of establishing the protocol, carrying out the analyses and interpreting the results. This also includes the full right to publish the results without limitation.

\section{Author details}

${ }^{1}$ IGES Institut GmbH, Friedrichstraße 180, 10117 Berlin, Germany. ${ }^{2}$ Roche Pharma AG, Grenzach-Wyhlen, Germany. ${ }^{3}$ InGef - Institute for Applied Health Research Berlin GmbH, Berlin, Germany. ${ }^{4}$ Department of Health Sciences / Public Health, Med. Faculty, TU Dresden, Dresden, Germany. ${ }^{5}$ Department of Public Health, Health Services Research and HTA, UMIT, Hall in Tirol, Austria.

Received: 12 July 2019 Accepted: 5 December 2019

Published online: 10 December 2019

\section{References}

1. Walker FO. Huntington's disease. Lancet. 2007;369(9557):218-28,

2. Ross CA, Aylward EH, Wild EJ, Langbehn DR, Long JD, Warner JH, Scahill RI, Leavitt BR, Stout JC, Paulsen JS, et al. Huntington disease: natural history, biomarkers and prospects for therapeutics. Nat Rev Neurol. 2014;10(4):204-16.

3. McColgan P, Tabrizi SJ. Huntington's disease: a clinical review. Eur J Neurol. 2017;25(1):24-34.

4. Singer C. Comprehensive treatment of Huntington disease and other choreic disorders. Cleve Clin J Med. 2012;79(Supplement 2):S30-4.

5. Roos RAC. Huntington's disease: a clinical review. Orphanet J Rare Dis. 2010; $5 \cdot 40$

6. Pringsheim T, Wiltshire K, Day L, Dykeman J, Steeves T, Jette N. The incidence and prevalence of Huntington's disease: a systematic review and meta-analysis. Mov Disord. 2012;27(9):1083-91.

7. Rawlins MD, Wexler NS, Wexler AR, Tabrizi SJ, Douglas I, Evans SJ, Smeeth L. The prevalence of Huntington's disease. Neuroepidemiology. 2016;46(2): $144-53$.

8. European Parliament. Regulation (EC) No 141/2000 of the European Parliament and of the council of 16 December 1999 on orphan medicinal products. Brussels: European Parliament; 2000

9. Kay C, Skotte NH, Southwell AL, Hayden MR. Personalized gene silencing therapeutics for Huntington disease. Clin Genet. 2014;86(1):29-36.

10. Przuntek $\mathrm{H}$, Steigerwald A. Epidemiologische Untersuchung zur Huntington'schen Erkrankung im Einzugsgebiet der Würzburger Neurologischen Universitätsklinik unter besonderer Berücksichtigung des unterfränkischen Raumes. Nervenarzt. 1987:58:424-7.

11. Wendt GG, Drohm D. Huntington's chorea. A population-genetic study. Die Huntingtonsche Chorea. In: Humangenetic: Advances in Human Genetics. Stuttgart: Thieme; 1972. p. 1-121.

12. Busse M, Al-Madfai DH, Kenkre J, Landwehrmeyer GB, Bentivoglio A, Rosser A. European Huntington's Disease N: utilisation of healthcare and associated Services in Huntington's disease: a data mining study. PLoS Curr. 2011;3: RRN1206.

13. Andersohn F, Walker J. Characteristics and external validity of the German health risk institute (HRI) database. Pharmacoepidemiol Drug Saf. 2016;25(1): 106-9.

14. Baig SS, Strong M, Quarrell OW. The global prevalence of Huntington's disease: a systematic review and discussion. Neurodegenerative Dis Manag. 2016:6(4):331-43.

15. Evans SJ, Douglas I, Rawlins MD, Wexler NS, Tabrizi SJ, Smeeth L. Prevalence of adult Huntington's disease in the UK based on diagnoses recorded in general practice records. J Neurol Neurosurg Psychiatry. 2013;84(10):1156-60

16. Sipilä J, Päivärinta M. Why we still need more research on the epidemiology of Huntington's disease. Neuroepidemiology. 2016;46:154-5.

17. Loy CT, Lownie A, McCusker E. Huntington's disease. Lancet. 2010;376(9751): 1463.

18. Warby SC, Visscher H, Collins JA, Doty CN, Carter C, Butland SL, Hayden AR, Kanazawa I, Ross CJ, Hayden MR. HTT haplotypes contribute to differences in Huntington disease prevalence between Europe and East Asia. Eur J Hum Genet. 2011;19(5):561-6.
19. Fisher ER, Hayden MR. Multisource ascertainment of Huntington disease in Canada: prevalence and population at risk. Mov Disord. 2014:29(1):105-14.

20. Sipilä JO, Hietala M, Siitonen A, Paivarinta M, Majamaa K. Epidemiology of Huntington's disease in Finland. Parkinsonism Relat Disord. 2015;21(1):46-9.

21. Carrassi E, Pugliatti M, Govoni V, Sensi M, Casetta I, Granieri E. Epidemiological study of Huntington's disease in the province of Ferrara, Italy. Neuroepidemiology. 2017;49(1-2):18-23.

22. Wexler NS, Collett L, Wexler A, Rawlins MD, Tabrizi SJ, Douglas I, Smeeth L, Evans SJ. Incidence of adult Huntington's disease in the UK: a UK-based primary care study and a systematic review. BMJ Open. 2015; https://bmjopen bmj.com/content/bmjopen/6/2/e009070.full.pdf. Cited 2019 Mar 13.

23. Paulsen JS, Nehl C, Hoth KF, Kanz JE, Benjamin M, Conybeare R, McDowell B, Turner B. Depression and stages of Huntington's disease. Neuropsychiatry Clin Neurosci. 2005;17(4):496-502.

24. Divino V, Dekoven M, Warner JH, Giuliano J, Anderson KE, Langbehn D, Lee WC. The direct medical costs of Huntington's disease by stage. A retrospective commercial and Medicaid claims data analysis. J Med Econ. 2013;16(8):1043-50.

25. van Walsem MR, Howe El, Ruud GA, Frich JC, Andelic N. Health-related quality of life and unmet healthcare needs in Huntington's disease. Health Qual Life Outcomes. 2017;15(1):6.

26. Noyes K, Liu H, Lyness JM, Friedman B. Medicare beneficiaries with depression: comparing diagnoses in claims data with the results of screening. Psychiatr Serv. 2011;62(10):1159-66.

27. Frank J. Comparing nationwide prevalences of hypertension and depression based on claims data and survey data: an example from Germany. Health policy. 2016;120(9):1061-9.

28. Busch MA, Maske UE, Ryl L, Schlack R, Hapke U. Prevalence of depressive symptoms and diagnosed depression among adults in Germany: results of the German health interview and examination survey for adults (DEGS1). Bundesgesundheitsblatt Gesundheitsforschung Gesundheitsschutz. 2013:56(5-6):733-9.

29. Stout JC, Paulsen JS, Queller S, Solomon AC, Whitlock KB, Campbell JC, Carlozzi N, Duff K, Beglinger LJ, Langbehn DR, et al. Neurocognitive signs in prodromal Huntington disease. Neuropsychology. 2011:25(1):1-14.

30. Paulsen JS, Langbehn DR, Stout JC, Aylward E, Ross CA, Nance M, Guttman M, Johnson S, MacDonald M, Beglinger $L$, et al. Detection of Huntington's disease decades before diagnosis: the predict-HD study. J Neurol Neurosurg Psychiatry. 2008;79(8):874-80.

31. Beglinger $\sqcup$, O'Rourke JJ, Wang C, Langbehn DR, Duff K, Paulsen JS. Huntington study group I: earliest functional declines in Huntington disease. Psychiatry Res. 2010;178(2):414-8.

32. Peavy GM, Jacobson MW, Goldstein JL, Hamilton JM, Kane A, Gamst AC, Lessig SL, Lee JC, Corey-Bloom J. Cognitive and functional decline in Huntington's disease: dementia criteria revisited. Mov Disord. 2010;25(9):1163-9.

33. Paulsen JS. Cognitive impairment in Huntington disease: diagnosis and treatment. Curr Neurol Neurosci Rep. 2011;11(5):474-83.

34. Anderson KE, Divino V, DeKoven M, Langbehn D, Warner JH, Giuliano J, Lee WC. Interventional differences among Huntington's disease patients by disease progression in commercial and medicaid populations. J Huntingtons Dis. 2014;3(4):355-63.

35. Rocha NP, Mwangi B, Gutierrez Candano CA, Sampaio C, Furr Stimming E, Teixeira AL. The Clinical Picture of Psychosis in Manifest Huntington's Disease: A Comprehensive Analysis of the Enroll-HD Database. Front Neurol. 2018:9:930

36. Orth M, Handley OJ, Schwenke C, Dunnett SB, Craufurd D, Ho AK, Wild E, Tabrizi SJ, Landwehrmeyer GB. Investigators of the European Huntington's Disease N: Observing Huntington's disease: the European Huntington's disease Network's REGISTRY. PLoS Curr. 2010;2:RRN1184.

37. Burgunder J, Guttman M, Perlman S, Goodman N, van Kammen D, Goodman L. An International Survey-based Algorithm for the Pharmacologic Treatment of Chorea in Huntington's Disease. PLoS Curr. 2011;3:RRN1260

38. Coppen EM, Roos RAC. Current pharmacological approaches to reduce chorea in Huntington's disease. Drugs. 2017;77(1):29-46.

39. Mason SL, Barker RA. Advancing pharmacotherapy for treating Huntington's disease: a reviewof the existing literature. Expert Opin Pharmacother. 2015;17(1):41-52

40. Jones C, Busse M, Quinn L, Dawes H, Drew C, Kelson M, Hood K, Rosser A, Edwards RT. The societal cost of Huntington's disease: are we underestimating the burden? Eur J Neurol. 2016;23(10):1588-90.

\section{Publisher's Note}

Springer Nature remains neutral with regard to jurisdictional claims in published maps and institutional affiliations. 